\title{
Empresas do comércio "em grosso" na economia de Goiânia, cidade em formação (1933-1963)
}

\author{
Companies of Commerce "wholesale" in the Economy of Goiânia, \\ City in Formation (1933-1963)
}

\begin{abstract}
Dulce Portilho Maciel
Universidade Estadual de Goiás -UEG, Brasil , Programa de Pós-Graduação em

Territórios e Expressões Culturais no Cerrado - TECCER

http://orcid.org/0000-0001-5094-1819

dportilho@uol.com.br, teccer.ueg@gmail.com
\end{abstract}

Fecha de recepción: 01 de agosto de 2016

Fecha de aceptación: 25 de noviembre de 2016

Sugerencia de citación: Maciel, D. (2017). Empresas do comércio "em grosso" na economia de Goiânia, cidade em formação (1933-1963).

tiempo\&economía, 4(1), 85-99, doi: http://dx.doi.org/10.21789/24222704.1184

\section{RESUMO}

Este texto refere-se aos primeiros trinta anos de Goiânia, cidade fundada em 1933, para servir de capital ao estado de Goiás (Brasil). A pesquisa que o fundamenta tomou como modelo de classificação das atividades comerciais o Censo brasileiro de 1950, que desdobra o comércio "em grosso" em dois ramos: o atacadista em si e o misto, este, composto por estabelecimentos que atuam tanto no atacado como no varejo. A pesquisa revela um vigoroso desempenho do comércio misto, comparativamente ao atacadista. Atribuímos o maior êxito do primeiro ao fato de a área varejista deste voltar-se para o abastecimento da própria cidade de Goiânia, cujo aumento populacional e modernização dos costumes têm produzido, localmente, uma demanda por mercadorias sempre em excepcional crescimento. 
Palavras-chave: Goiânia, comercio atacadista, comercio misto, crescimento populacional,modernização dos costumes, abastecimento

Códigos JEL: F14, Q56, J22

\section{ABSTRACT}

This text refers to the first thirty years of Goiânia, city founded in 1933, to serve as capital to the state of Goyaz (Brazil). The research that bases it took as a model of classification of the commercial activities the Brazilian Census of 1950, that unfolds the trade "in bulk" in two branches: the wholesaler itself and the mixed one, this one composed by establishments that act in the wholesale as much In retail. The research reveals a vigorous performance of mixed trade compared to wholesaler. We attribute the greatest success of the former to the fact that the retail area of this one turns to the supply of the city of Goiânia itself, whose population increase and modernization of customs have locally produced a demand for merchandise always in exceptional growth.

Keywords: Goiânia, wholesale, mixed trade, population growth, modernization of customs, supply

JEL Codes: F14, Q56, J22 


\section{Introdução}

Goiânia foi fundada em 1933, para servir de nova sede ao governo estadual goiano, em substituição à cidade de Goiás, antiga Vila Boa. Foi a segunda capital de estado, no Brasil, a ser implantada conforme um projeto urbanístico previamente concebido - seguindo-se a Belo Horizonte (estado de Minas Gerais). Na época, o estado de Goiás apresentava pequena taxa populacional, caracterizando-se por um baixo índice de urbanização, com cerca de $80 \%$ da população residindo no campo; reduzida atividade comercial interna, havendo supremacia de uma agro-pecuária de subsistência, fundada em unidades de produção dispersas no território; escasso e irregular intercâmbio econômico e cultural com outras regiões brasileiras, predominantemente com a Sudeste; precário sistema público de arrecadação fiscal, exibindo aquela unidade federada um dos menores orçamentos estaduais do país; assim, por diante. Nestas condições, a população goiana, em sua maioria, caracterizava-se por um modo de vida extraordinariamente rústico, à maneira como ocorria em outras regiões brasileiras, na época, igualmente isoladas, econômica e culturalmente, do restante do país.

A escolha da área para instalação da nova cidade foi precedida de minuciosos estudos técnicos, não apenas em termos fisiográficos (topografia, clima, recursos hídricos, etc.) mas, sobretudo, no concernente às condições requeridas para sua localização no território, levando-se em conta fatores que pudessem favorecer o desenvolvimento de comunicações e de intercâmbio comercial com as regiões mais desenvolvidas do país (sobretudo a Sudeste), propiciando, assim, o crescimento econômico e populacional, bem como a modernização cultural do estado de Goiás.

As atividades comerciais abrangem, conforme classificação tradicional, o comércio atacadista e o varejista, efetuados por estabelecimentos ou indivíduos autônomos. A pesquisa em que se baseia o presente trabalho, entretanto, tomou o Censo brasileiro de 1950 como modelo de classificação das atividades comerciais. Este Censo, diferentemente daquela classificação, exclui os vendedores autônomos, inclui as firmas do comércio de imóveis e desdobra o comércio grossista em dois ramos: o comércio atacadista e o comércio misto: estabelecimentos que atuam tanto no comércio atacadista como no varejista.

Esta classificação é adequada ao estudo das condições pelas quais funcionava a economia de Goiânia, nos seus primeiros trinta anos. Naquela fase, a divisão do trabalho entre estabelecimentos empresariais não se achava bem definida, visto que a especialização das unidades e a intercomplementaridade delas não era ainda uma exigência vital ao desenvolvimento econômico daquele centro urbano-capitalista em processo de formação.

O presente artigo baseia-se em dados originais coletados nos arquivos da Junta Comercial do estado de Goiás, recaindo o enfoque da pesquisa sobre o comércio exclusivamente atacadista, o misto e o de imóveis, levados a efeito por empresas organizadas sob a forma de sociedades ou cooperativas, com duração mínima de cinco anos. Abandonamos as do comércio exclusivamente varejista, por ser ele constituído sobretudo de pequenos negócios, também as firmas do tipo jurídico "individual", pelo mesmo motivo, e as com duração inferior a cinco anos, em razão disto indicar baixo grau de solidez em tais organizações.

O segmento mais importante das atividades comerciais em Goiânia, no período considerado (1933-1963) era o do comércio misto. Contudo, vamos aqui tratar primeiro do comércio 
atacadista, em virtude de ter-se constituído ele em principal foco de nossa atenção, no desenvolvimento da pesquisa em pauta. Os dados a respeito do comércio de imóveis serão examinados em outra oportunidade, em face dos limites estabelecidos para a extensão deste trabalho.

\section{Comércio atacadista}

Nosso interesse pelo comércio atacadista decorreu do fato de uma hipótese inicial de trabalho referir-se a esse ramo de atividade. Nossa hipótese era que, bem possivelmente, a empresa mercantil atacadista teria se achado entre os agentes que, estando em condições de centralizar volume considerável de capitais em seu poder, teriam investido uma parcela deles na atividade produtiva daquela cidade. Esta hipótese baseara-se na afirmação até agora consagrada na bibliografia produzida a respeito do desenvolvimento econômico de Goiânia, de que a principal função da cidade teria sido a de entreposto comercial -ou "empório"-, mediante o grande capital atacadista. (Bertran, 1984, 1988; Miranda, 1980; Gonçalves, 1984)

A atuação da empresa mercantil -situada no campo da circulação de mercadorias- pressupõe a existência de um sistema produtivo em separado. O comércio atacadista, em razão do monopólio que exerce sobre os mercados, tem carreado para as cidades que o abrigam excedentes produzidos alhures e, a partir de certo ponto da concentração de capitais em seu poder, freqüentemente tem passado a atuar na atividade produtiva urbana em si, encontrando, por essa via, novas formas de acumulação. (Solis, 1989, passim)

Apesar de tudo, as nossas expectativas acerca do comércio atacadista, no caso de Goiânia, frustraram-se em grande parte, devido aos resultados obtidos mediante a pesquisa que levamos a efeito: nem o comércio atacadista fora tão forte na economia da cidade como se pretendia (melhor foi o desempenho do comércio misto, mas também nem tanto); e tampouco o capital concentrado nele veio a servir ali de poderosa mola ao desenvolvimento das atividades produtivas propriamente ditas.

A respeito do grande comércio, estritamente, é provável que tenham tido uma parcela de razão alguns autores (Ferrari, 1988; CIC, 1949; IBGE, 1957), que apontaram Anápolis como o principal centro econômico de Goiás, mesmo já depois de instalada a nova Capital, em decorrência de ter-se situado ali, por longo tempo, o ponto terminal da única linha férrea a servir todo aquele estado e também outras áreas do Centro-Oeste brasileiro até 1951, quando se inaugurou a estação de Goiânia. As precárias condições técnicas das estradas de rodagem existentes no Brasil e particularmente naquela região, até a segunda metade daquela década, tornavam excessivamente elevados os custos de transporte por essa via, sobretudo para mercadorias muito volumosas. E este era o caso da produção agropecuária destinada a exportação, por toda aquela grande área do país. Ainda em 1960, 80\% das exportações agrícolas de Goiás eram feitas por via férrea. (Governo Mauro Borges, 1961). Mesmo então, uma parcela considerável do gado bovino de exportação - difícil de ser precisada, em face das características especiais desta mercadoria- transportava-se a outros mercados a pé.

Isto, não obstante o grande aumento das vias de transporte rodoviário ocorrido ali, a partir de 1930. Segundo Katzman (1977), entre este ano e o de 1937, as estradas de rodagem em Goiás dobraram em número de quilômetros construídos e, daí até 1939, quase alcançaram o 
dobro outra vez. Por volta de 1940, a relação entre Km2 de estrada construída e extensão territorial era, em Goiás, idêntica à da média nacional. Quanto à extensão destas vias por habitante, porém, este estado achava-se, de acordo com o autor, em segundo lugar no Brasil.

Apesar disto, a deficiência das condições técnicas mediante as quais a maior parte das estradas goianas foi construída, até meados de 1950 -sem ou com pequena concorrência de máquinas e pessoal qualificado nesta área-, somada, entre outros fatores, aos estragos que o tráfego de carros de bois produzia nelas, à reduzida quantidade de veículos automotores de carga em circulação e muitos outros, entretanto, faziam com que os custos de transporte entre aquele estado e outras regiões do Brasil somente fossem compensadores para mercadorias com alta densidade de valor. Este é o caso sobretudo dos produtos transformados industrialmente, que portam dada quantidade de valor agregado a seus custos de produção.

Goiânia constituiu-se, desde sua fundação, em centro radial do sistema rodoviário do Estado de Goiás e, partir de 1951, substituiu Anápolis na função de ponto terminal de cargas no que se refere à estrada-de-ferro. Não obstante a precariedade de tais vias, ao que tudo indica, Goiânia firmou-se, logo a seguir, no papel de "capital comercial do estado" de Goiás (na expressão de Bertran,1988). Isto é, bem antes do que muitos pretendem, inclusive este autor, que situa tal fato na década de 1970.

Referindo-nos, a partir de agora, à Tabela 1, apresentada atrás, alertamos para o fato de o comércio atacadista ter surgido já um tanto tardiamente na economia de Goiânia (período 1940-45), em relação a outros gêneros de atividades econômicas. Isto parece natural, em face das dificuldades então oferecidas ao transporte de cargas pesadas de e para esta cidade, e também porque se trata de um ramo de negócios que, em regra, exige substancial inversão de capitais. Antes disso, qualquer iniciativa nessa área poderia representar grande risco, posto que nem mesmo as funções administrativas da cidade achavam-se formalmente estabelecidas, a inauguração oficial da nova Capital goiana ocorreu em 1942.

Nesse gênero de comércio, o ramo mais desenvolvido foi o de produtos agropecuários e extrativos, como se poderia esperar, uma vez que o setor primário era de todos o mais forte na economia do estado de Goiás e que boa parcela de sua produção destinava-se ao abastecimento da população e das indústrias de centros urbanos localizados em outras regiões brasileiras. Este ramo de atividades apresentou-se com $11 \%$ do total das empresas consideradas na Tabela 1 e idêntico percentual na formação da soma do capital por elas investido.

Por outro lado, a via inversa para produtos industrializados era uma possiblidade a ser explorada, em face da grande transformação que se vinha processando na sociedade goiana, desde a época da fundação da nova Capital, quanto ao seu modo de vida: aumento da renda, mercantilização das relações de produção, monetarização do consumo, negação de maneiras "arcaicas" de fazer e pensar, etc. As concomitantes mudanças verificadas no quadro econômico, sócio-cultural e mesmo geo-político do Brasil -a política de integração econômica do território nacional, então levada a efeito pelo governo federal, tinha também o sentido de promover a sua unidade cultural- concorreriam para possibilitar o estabelecimento de liames cada vez mais estreitos entre essa nova área do mercado interno e o setor industrial do país. Sintomaticamente, o ramo do comércio atacadista que secundou o de produtos primários, ainda que a grande distância, foi o de máquinas, aparelhos e material elétrico, $2 \%$ das empresas e também do capital considerados na Tabela 1. 


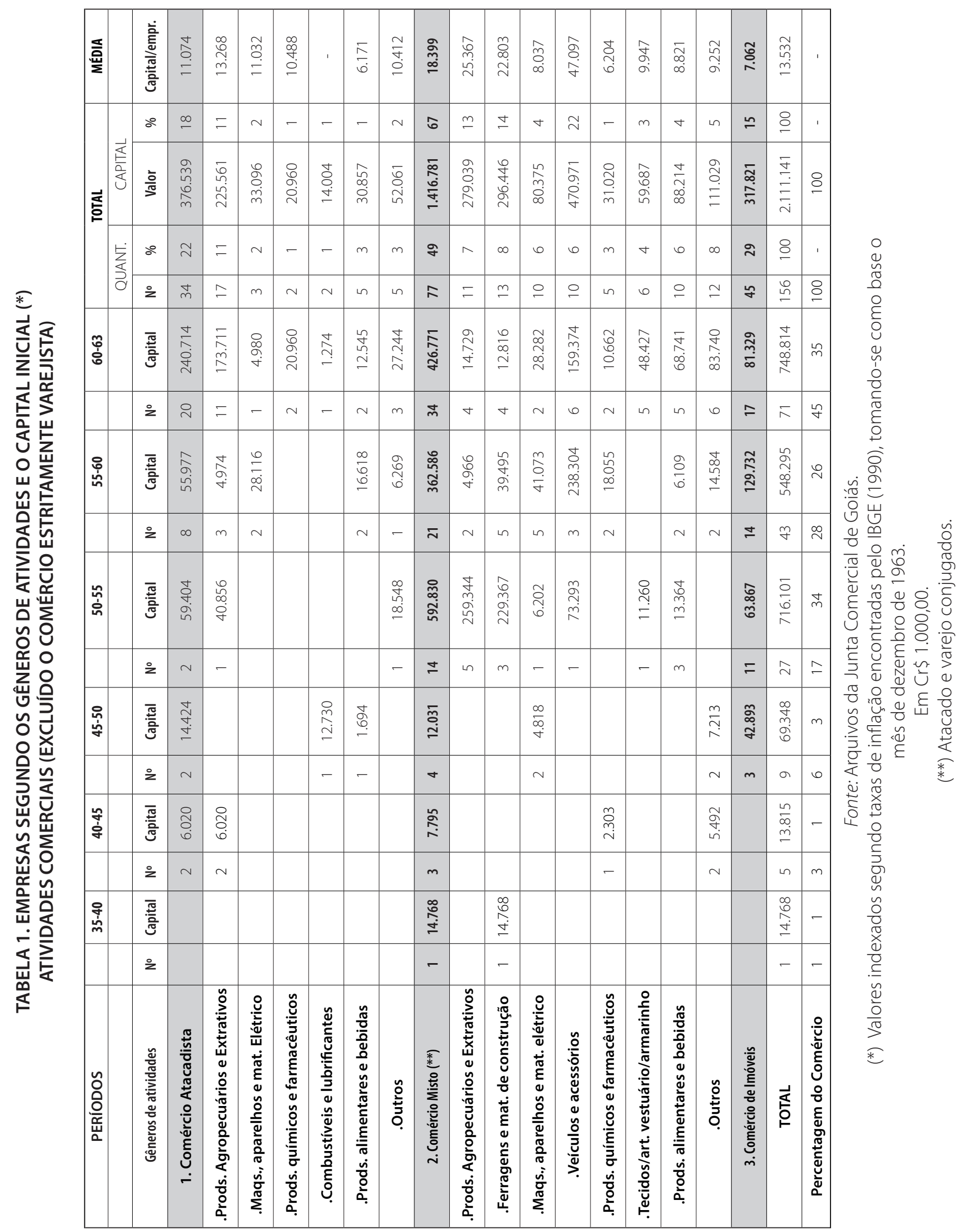


Até meados de 1950, também as condições das vias férreas que serviam a Goiás ${ }^{1}$ significavam empecilho a esse intercâmbio, o que se constituía em motivo de grande preocupação para o governo goiano, principalmente para seus parlamentares, costumeiramente, bastante sensíveis às demandas dos grupos de interesse que representam:

Que a Assembléia dirija ao Presidente da República e ao Ministro da Viação solicitação de recursos materiais para a Estrada de Ferro Goiás e a Mogiana para que se possa acudir a situação que já se prevê angustiosa para o Estado de Goiás... Ambas as estradas não se encontram aparelhadas para transportar o enorme volume da safra goiana e isto virá estancar uma das maiores fontes econômicas deste Estado².

Já antes daquela época, entretanto, esse intercâmbio vinha deixando de ocorrer exclusivamente sob a forma simplificada de produtos primários versus bens industrializados. Desde a primeira década da construção de Goiânia que as atividades de processamento de matérias primas em Goiás vinham proporcionando a essa cidade alguma fonte de receita, via comércio externo: arroz e outros grãos beneficiados, charque, laticínios, madeira, cal, etc. ${ }^{3} \& \&$ Logo em seguida, as usinas de açucar, álcool e subprodutos -indústria de tecnologia mais sofisticada e, portanto, mais intensiva em capital que as anteriores- passaram a incluir sua produção na pauta de exportações da cidade.

No comércio atacadista de Goiânia, tiveram também certo destaque, nos primeiros trinta anos da cidade, o de produtos alimentares e bebidas e o de combustíveis e lubrificantes respectivamente, $3 \%$ das empresas e $1 \%$ do capital, e $1 \%$ das empresas assim como do capital, considerados na Tabela 1. Estabelecidos ambos no período 1945-50, a presença deles ali guarda relação com o atendimento a necessidades recém surgidas naquela sociedade -tanto em nível local quanto estadual-, para uma parcela crescente da população que ía aderindo a novos hábitos de consumo, incluindo-se aí os alimentos industrializados e os veículos automotores, estes, para o transporte de cargas e passageiros, mas também a produção agrícola.

No período aqui em causa, a transformação de produtos alimentares era o gênero de indústria mais desenvolvido em Goiânia, sendo que uma parte significativa de sua produção destinava-se ao mercado externo à cidade. Assim, muito embora inicialmente, na vida econômica daquela cidade, a função do mercado atacadista de alimentos tivesse sido a de exportar principalmente produtos in natura e importar gêneros industrializados, mais tarde, este movimento inverteu-se; isto é: a indústria goianiense passou a captar e transformar uma parte da produção agropecuária do Estado de Goiás e de outras áreas da região Centro-Oeste e o seu comércio atacadista -e também o misto- a encarregar-se de distribuir essa produção da indústria local a diferentes mercados.

1 E. F. Goiás e E. F. Mogiana, esta última pertencente ao estado de São Paulo, mas que alcançava Uberlândia, município do estado de Minas Gerais, próximo ao sudoeste de Goiás, na época, a região mais próspera deste estado.

2 Arquivo da Assembléia Legislativa do Estado de Goiás (AALEG): Pasta do deputado F. do Espírito Santo, requerimento de sua autoria, datado de 19/04/55.

3 Pedro Ludovico Teixeira, Relatório apresentado ao Exmo. Snr. Presidente da República pelo Dr. Pedro Ludovico Teixeira, Interventor Federal - 1939, Goiânia, Imprensa Oficial, 1939.

tiempo\&economía Vol. 4 N. ${ }^{\circ} 1$ - I semestre de 2017 
Para que se compreenda a questão dos combustíveis e lubrificantes, convém que se explique que, até a década de 1930, a maior parte do transporte em Goiás era feita em carros de bois e em lombos de bestas, inclusive das cargas que se destinavam ou provinham das estações da estrada-de-ferro, mercadorias do comércio "em grosso" de exportação e importação. Mesmo nos trabalhos da construção de Goiânia - pavimentação de vias públicas, transporte de materiais, etc.- o uso de parelhas e de carros de bois era uma rotina nos primeiros tempos da cidade. Em todo o Estado, trafegava reduzidíssimo número de veículos de passeio e de transporte interurbano de passageiros, e eram também poucos os caminhões, mesmo porque era pequena a extensão das estradas de rodagem e precaríssimo o seu estado de conservação. A construção e exploração delas estavam a cargo da iniciativa privada. A partir de então, a situação transformou-se muito rapidamente e, entre os tantos resultados disto, um foi o aumento crescente do consumo de combustíveis e lubrificantes.

Por último, com referência ao comércio atacadista de Goiânia, cabe que se mencione o de produtos químicos e farmacêuticos, surgido ali somente no início da década de 1960. A instalação deste ramo de negócios mediante estabelecimentos de porte considerável era reflexo, certamente, de mais uma mudança que vinha ocorrendo, cada vez mais generalizadamente, nos hábitos de consumo e nos métodos de reprodução da vida adotados pela população, assim como na exploração das forças produtivas internas, uso cada vez mais corriqueiro de produtos medicinais e veterinários industrializados, assim como, crescentemente, o de fertilizantes, inseticidas e outros insumos agrícolas.

\section{Comércio misto}

Neste gênero de comércio, o segmento de veículos e acessórios destacou-se largamente dos demais em Goiânia ( $6 \%$ das empresas incluídas na Tabela 1), mas realçando-se pelos $22 \%$ que atingiu da soma do capital delas. Foi ele um dos ramos de atividades a apresentar mais elevada média de capital por empresa, em Goiânia, superado apenas pela indústria de transformação de borracha -uma vez que se tratava, neste caso, basicamente da reforma de pneumáticos e outras peças e acessórios de veículos- e a de extração vegetal. Surgiu ali no período 1950-55, com uma única empresa que, como se pode imaginar, era representante de uma fábrica estrangeira. (ACIEG, 1985). Cresceu extraordinariamente na fase seguinte -ocasião em que a indústria de veículos automotores estabelecia-se com peso na economia nacional-, sobretudo quanto ao volume do capital investido. Permaneceu crescendo entre 1960 e 1963; desta vez, porém, principalmente quanto ao número de unidades comerciais instaladas, significando isto uma média capital-empresa reduzida, em comparação com a fase anterior.

Algumas das empresas desse ramo do comércio misto passaram depois a atuar na comercialização de equipamentos de grande porte, veículos pesados e utilitários em geral -para a agropecuária, mineração, extração vegetal, construção civil, transporte de cargas, transporte coletivo de passageiros, etc. Elas detinham, em 1985, o monopólio do comércio de equipamentos e veículos pesados no estado de Goiás e outras partes das regiões Centro-Oeste, Norte e Nordeste do país. Duas destas empresas possuíam, em 1985, unidades subsidiárias dedicadas ao setor produtivo da economia goiana: à agropecuária e à agro-indústria, sendo que uma delas, também à fabricação de máquinas agrícolas. (Ibid., 48, 59, e Gonçalves, 1984). 
Foi extraordinário, em Goiás, o processo de transformação ocorrido no campo, a partir dos anos 1930, representado pela passagem de maneiras de produzir inteiramente tradicionais, ao predomínio do modo moderno ou industrial de produção - isto é, o que associa insumos e serviços industriais com terra e trabalho. É bem verdade que já nas primeiras décadas do Século xx, em algumas áreas do estado de Goiás, principalmente na assim chamada Região da Estrada de Ferro, algumas unidades produtoras rurais utilizavam-se de instrumentos agrícolas então considerados modernos, como o arado de ferro, a grade e a semeadeira. (Borges, 1990), isto era exceção, contudo. A regra geral, naquele Estado, era a da utilização, na agricultura, do sistema de "coivara" (herdado de nossos índios), associado ao uso de instrumentos rudimentares de ferro, como a enxada, o enxadão, o machado, etc. e, na pecuária, a do aproveitamento de pastagens naturais, combinado ou não com o cultivo de uns poucos "pastos", para uso em condições especiais - ocasiões de seca prolongada, alimentação de animais muito jovens, etc.

Desde 1940, entretanto, uma série de medidas do governo federal e estadual, como a colonização planejada (inclusive com estrangeiros), a criação de estações agrícolas experimentais e de fazendas-modelo, o estímulo ao cooperativismo rural, a oferta de financiamento e outras facilidades à importação de reprodutores, entre muitas outras, certamente que concorreram para que, a partir da década seguinte, ganhasse impulso em Goiás, particularmente na sua parte sul (grosso modo, seu atual território; isto é, como ficou após seu desmembramento, para formação do atual estado do Tocantins), um intenso processo de modernização tecnológica do campo.

No município de Goiânia, os estímulos oficiais à modernização rural foram ainda maiores. A ação do governo estadual, iniciada logo após a fundação da cidade, abrangeu medidas como: criação, na sua zona urbana, de um horto florestal (e parque educativo); doação de mudas; venda a preços simbólicos ou doação de chácaras a particulares, sob a condição de que nelas fosse desenvolvida produção intensiva de alimentos e muitas outras ${ }^{4}$. A partir de 1962, uma instituição oficial, o Instituto de Desenvolvimento Agrário de Goiás -IDAGO- passou a exercer o papel de coordenador desse processo em todo o Estado. (Rabelo, 1978)

Um dos mais importantes indicadores para a avaliação do nível de modernização da agricultura é o grau de sua mecanização. Um estudo estatístico realizado por F. Itami Campos a respeito desta questão em Goiás fornece-nos elementos muito relevantes nesse sentido:

[Em 1950, o Estado de Goiás] tinha menos de 90 tratores, registrava-se a razão de um trator para cada 5.224 hectares de lavoura e um arado para cada 235 hectares... Em 1960, o número de tratores cresce mais de $1.400 \%$ (em relação a 1950), sendo que a razão trator por hectare de lavoura cai para 732 e de arado por hectare de lavoura para 152... Em 1970... o número de tratores cresce em mais de 300\% (em relação a 1960), sendo que a razão trator por hectare de lavoura reduziu-se para 287 e de arado para 54. (Campos, 1985, p. 32)

Na avaliação da intensidade da mudança ocorrida no setor agrário da economia de Goiás, estes dados, embora ofereçam já uma noção, podem ainda adquirir um outro significado se

4 A respeito da ação do governo estadual, baseamo-nos nos seguintes documentos: Relatório da Superintendência das Obras de Goiânia, de junho de 1936 (Monteiro, 1938, pp. 452 e ss); Relatório Semanal de Serviços pela Diretoria Geral de Produção e Trânsito, de 23/01/39 em Arquivo Pedro Ludovico (APL) Pasta 134; Jeronimo Coimbra Bueno, Mensagem apresentada à Assembléia Legislativa do Estado de Goiás, ao iniciar-se a 1a sessão ordinária de 1950, Diário Oficial do Estado de Goiás, Ano 113, No. 6.211, de 15/07/50.

tiempo\&economía Vol. 4 N. ${ }^{\circ} 1$ - I semestre de 2017 
considerarmos que, na realização dos cálculos, o autor do trabalho tomou como referência as terras cultivadas em toda a antiga extensão desse estado, quando, em realidade, a disseminação da agricultura mecanizada estava se processando quase exclusivamente na sua parte sul, isto é, na área que hoje grosseiramente constitui o território do estado daquele nome. Para que se possa compreender melhor o êxito alcançado pelo ramo comercial de veículos e acessórios na economia de Goiânia, é necessário ainda que mencionemos o fato de que a modernidade, uma vez conhecida pela população goiana - de forma cada vez mais generalizada desde a fundação de sua nova Capital-, vem marcando intensamente todo o seu modo de vida, incluindo-se aí os habitos de consumo em geral e, em particular, o de meios de transporte pessoal. A partir dos últimos anos de 1950, o uso de veículos de passeio, em substituição aos animais de montaria, veio se banalizando entre as camadas mais elevadas da sociedade, inclusive as residentes na zona rural.

O segundo ramo de maior êxito no comércio misto de Goiânia foi o de ferragens e material de construção, conforme os dados da Tabela 1 ( $8 \%$ do número das empresas nela consideradas e $14 \%$ da soma do capital). Tal desempenho não surpreende, posto que essa atividade exerce função de complementaridade em relação às industrias da construção civil, de transformação de minerais não-metálicos e metalúrgica, ramos muito desenvolvidos da economia urbana daquela cidade. Também não oferece surpresa a precocidade de seu surgimento naquela localidade, período de1935 a 1940, em face da grande demanda por essas mercadorias que desde cedo se estabelecera na área destinada a constituir-se em sede administrativa do estado de Goiás. Achava-se, nesse periodo, em pleno andamento, a extraordinária faina representada pelas atividades de edificação da nova cidade.

Esse ramo de negócios, por outro lado, bem provavelmente, começou logo em seguida a atender também a algumas regiões interioranas de Goiás, em razão do pioneirismo da nova Capital na produção industrial de tais artigos no estado, e visto que a indústria da construção civil, antes desconhecida naquele território, em termos empresariais, desde 1940 iniciara ali seu processo de desenvolvimento -os censos econômicos de 1940 e de 1950 registraram, respectivamente, 3 e 10 empresas deste ramo de atividade estabelecidas no estado-o de 1960 não levantou dados a esse respeito. Em 1985, conforme a Associação Comercial e Industrial do Estado de Goiás -ACIEG-, a indústria goianiense de produtos metalúrgicos para a construção civil destinava boa parte de sua produção a outros Estados brasileiros. O comércio misto de ferragens e material de construção teve uma das mais elevadas médias de capital por empresa entre as atividades consideradas na Tabela 1.

O ramo de produtos agropecuários e extrativos foi, no comércio misto, o terceiro colocado entre os abrangidos na referida tabela, com $7 \%$ do total das empresas e $14 \%$ do capital. Surgiu um tanto tardiamente na economia da cidade (entre 1950 e 1955), em comparação, por exemplo, com o comércio atacadista desses mesmos itens (período1940-45). Contudo, ele apresentou uma média de capital por empresa superior ao deste último tipo de comércio, mais especializado em suas funções. O que se pode depreender disso é que no caso do comércio misto, a atividade atacadista dos estabelecimentos tenha se realizado principalmente junto a mercados de outras regiões e que, por outro lado, o veio de comercio varejista por ele explorado tenha sido o do abastecimento alimentar da própria cidade de Goiânia, àquela altura, em processo de excepcional crescimento, em relação a outros centros urbanos brasileiros. 
Em quarto lugar, no comércio misto de Goiânia, estiveram empatados o ramo de produtos alimentares e bebidas e o de máquinas, aparelhos e material elétrico - ambos com $6 \%$ das empresas consideradas na Tabela 1 e $4 \%$ do capital delas. No primeiro caso, a área atacadista de seus estabelecimentos deve ter atuado mais no sentido de abastecer mercados do interior do Estado de Goiás e o varejista para atender à demanda crescente por alimentos e bebidas da própria cidade de Goiânia. No segundo caso, eram os sinais de modernidade apresentando-se logo na vida da cidade e do Estado (período 1945-50), e já com força considerável.

O quinto lugar coube ao ramo de tecidos, artigos do vestiário e armarinho. Ele surgiu relativamente tarde na economia de Goiânia (período 1950-55). Estranhamos este fato porque um dos aspectos freqüentemente lembrados em depoimentos oferecidos por habitantes pioneiros de Goiânia tem sido o da mudança ocorrida nos costumes, quanto aos modos de se vestirem e se apresentarem os indivíduos, na nova comunidade urbana que ali ía se formando. A singeleza e rusticidade das antigas maneiras em sociedade deram lugar a outras mais sofisticadas, próprias às comunidades urbanas modernas. Tais novos costumes, partindo de Goiânia, difundiam-se rapidamente por todo o estado de Goiás. Veja-se como se referiu a este fenômeno o escritor goiano Bernardo Elis:

Para espanto dos moradores de Vila Boa, as pessoas nela residentes que tinham vindo para Goiânia ali retornavam cada fim de semana totalmente mudadas: ostentavam ótimos trajes da moda, exibiam anéis e relógios, possuíam automóvel, estavam loquazes, desembaraçadas, serelepes... O ex-vilaboense voltava para Goiânia e ficava na velha cidade o espanto: de onde, minha senhora Santana, de onde surgia tanta riqueza? (Elis,1985)

Em último lugar, entre os casos individualizados na tabela em referência, esteve o ramo de produtos químicos e farmacêuticos, $3 \%$ das empresas consideradas no conjunto desta tabela e 1\% do seu capital. Este gênero de comércio surgiu relativamente cedo em Goiânia (período de 1940 a 1945). Isto espelhava, certamente, ao contrário do que ocorreu no caso anterior, os novos hábitos goianienses e goianos, de consumo de serviços de saúde tecnicamente qualificados e de artigos farmacológicos industrializados, em substituição ao curandeirismo e à medicina natural.

Por tudo que viemos discorrendo até o momento estamos convencidos de que o maior estímulo ao incremento das atividades econômicas de Goiânia foi, ao longo do período por nós estudado, o próprio crescimento físico e populacional da cidade ${ }^{5}$ e o conseqüente desenvolvimento ali -e crescentemente em todo o Estado de Goiás- de modos de vida tipicamente urbanos e modernos, próprios das sociedades capitalistas do nosso tempo.

E isto somente foi possível porque houve, na região em que a nova cidade se localizou, um anterior e concomitante desenvolvimento das forças produtivas, tornando-as capazes de produzir excedentes econômicos cada vez mais consideráveis, a serem concentrados no seu

5 Goiânia foi planejada pelo urbanista Atílio Correa Lima, para abrigar 15.000 habitantes, o que deveria vir a ocorrer cerca de cinqüenta anos após a implantação da nova Capital - a cidade de Goiás, em mais de 200 anos, jamais alcançara a marca de 10.000 moradores. Aconteceu, porém, que em 1942, quando se inaugurou a nova cidade, o número de seus habitantes já ultrapassara aquela previsão. O Censo de 1940 encontrou no município (somadas áreas urbanas e rurais) uma população de 48.166 habitantes. O Censo de 1950 encontrou 53.389 habitantes, o de 1960 registrou a presença de 153.505 e o de 1970 contou 389.784 habitantes No ano 2000, Goiânia já ultrapassara a soma de um milhão de habitantes.

tiempo\&economía Vol. 4 N. ${ }^{\circ} 1$ - I semestre de 2017 
maior centro urbano. O processo de acumulação urbana na nova cidade, por seu turno, permitiu um simultâneo e crescente movimento de aperfeiçoamento das forças produtivas próprias, ao ponto de permitir que, a partir de certo momento, ela pudesse transferir a outros lugares uma parte de sua produção interna ${ }^{6}$.

\section{Observações acerca da economia de Goiânia - à guisa de conclusão}

Uma das tarefas que realizamos com relação aos dados coletados da documentação arquivada na Junta Comercial do Estado de Goiás foi a organização de uma lista das 100 maiores unidades empresariais estabelecidas em Goiânia durante o conjunto temporal abrangido em nossa pesquisa, observado o critério da ordem de grandeza do seu capital. Destas 100 empresas, 65 pertenciam ao setor secundário e as outras 35 ao setor terciário da economia da cidade.

Entre estas últimas, 26 (mais de dois terços delas, pois) atuavam nos serviços comerciais, sendo 6 no comércio atacadista -: 2 de produtos agropecuários e extrativos e 1 de cada um dos quatro outros ramos -, 16 no comércio misto -: 4 de veículos e acessórios; 3 de produtos agropecuários e extrativos; 3 de máquinas, aparelhos e material elétrico; 2 de ferragens e material de construção; etc. -., e 4 do comércio de imóveis. Das restantes, 7 empresas atuavam nos serviços de transporte -: 3 do transporte coletivo urbano e 4 do transporte interurbano de passageiros -, e 2 nos serviços de armazenagem.

Trouxemos aqui os dados acima porque eles demonstram alguns pontos para os quais desejamos chamar a atenção neste trabalho, acerca do desenvolvimento da economia urbana de Goiânia. Eles apontam, em primeiro lugar, para a primazia que tiveram ali as atividades produtivas propriamente ditas - ou seja, as realizadas pelo setor industrial da cidade. Eles reforçam, por outro lado, as inúmeras indicações que reunimos, ao longo dos estudos que temos realizado acerca de Goiânia, de que o setor comercial da cidade, principalmente o seu segmento atacadista, não teve ali o peso que lhe tem sido atribuído.

E tais dados apontam, ademais, para uma questão que representa uma das peculiaridades daquela cidade, isto é, a função que exerce de centro administrativo em relação a determinadas atividades econômicas do conjunto do Estado de Goiás. Este é o caso típico dos serviços de armazéns e silos, essenciais para o desenvolvimento da economia daquele Estado, ainda hoje predominantemente agrária. Estes serviços são as vezes considerados como parte do comércio e, mais particularmente, do seu segmento atacadista. Mas, ainda que o consideremos assim -o que faz crescer a importância deste setor no contexto da economia urbana de Goiânia-, devemos estar alertas para o fato de que as bases físicas de tais serviços localizavam-se principalmente fora desta cidade e mesmo do seu município.

6 Pesquisadora do IBGE, em publicação editada por este órgão em 1988, ao concluir exame dos dados econômicos da região Centro-Oeste do Brasil, afirma: "os Censos Econômicos mostraram que esses centros [Goiânia, Brasília e Anápolis] ocupam... as primeiras posições, tanto no valor da produção industrial (Goiânia coloca-se na primeira posição, com cerca de $18,24 \%$ do valor da produção regional e Brasília na terceira colocação, com 10,58\% - o segundo lugar é ocupado por Anápolis, com 11,77\%), quanto ao valor das receitas do comércio e dos serviços em 1980, Brasília e Goiânia ocuparam o primeiro e o segundo lugares na receita do comércio, o mesmo acontecendo na receita dos serviços". (Cardoso, 1988, p. 193) 
Discordamos de interpretações como a que explica o desenvolvimento de Goiás e sua inserção na economia capitalista brasileira exclusivamente em razão do aumento da demanda nacional por alimentos e matérias primas, a partir da implantação de um modelo econômico de base industrial no país; e também das que, adotando tal ponto de vista, explicam que este modelo exigia, para seu funcionamento, que aquele Estado se incorporasse a um sistema desigual de intercâmbio, em que a ele cabia, em relação a bens industrializados, unicamente a função de mercado consumidor. Discordamos, do mesmo modo, daquelas para as quais o papel desempenhado por Goiânia nessas novas condições do desenvolvimento brasileiro, tenha sido sempre o de mero "corredor" de mercadorias, num movimento de mão dupla em que Goiás e outras partes do Centro-Oeste exportam gêneros primários e importam bens industrializados.

O fraco desempenho do comércio exclusivamente atacadista na economia de Goiânia, comparativamente ao do setor produtivo industrial da mesma cidade, representa mais uma evidência, segundo nossa compreensão, de que os processos econômicos ocorridos em Goiânia, no transcorrer do período aqui em pauta, detiveram grau de complexidade bem superior ao que se entende. Atribuimos o maior êxito do comércio misto, em relação ao atacadista, ao fato de a área varejista do primeiro voltar-se para o abastecimento da própria cidade, cujo aumento populacional e modernização permanente dos modos de vida ali estabelecidos têm produzido, localmente, uma demanda sempre em excepcional crescimento, tanto por alimentos elaborados, como para outros bens industrializados de consumo final.

O comércio atacadista, levado a efeito tanto pelo ramo denominado misto, quanto pelo que atua exclusivamente no grande comércio, por seu lado, além de exportar produtos primários a mercados de outras regiões e importar deles produtos industrializados para consumo de sua população, tem também crescentemente exportado mercadorias transformadas industrialmente em Goiás e, principalmente, em Goiânia -neste caso, mais recentemente, inclusive bens de produção-, sendo que, muitas vezes, as importações dizem respeito a bens de produção ou de consumo intermediário, para o estabelecimento e expansão do setor industrial da cidade e do estado.

Muito embora tenhamos reservado para outras oportunidades o tratamento dos assuntos das origens do capital aplicado na economia urbana de Goiânia e das condições sob as quais ele se reproduziu ali, devemos informar, aqui, que muito pouco da soma aplicada empresarialmente naquela cidade era procedente do comércio atacadista e também que outros ramos de atividade revelaram-se bem mais atraentes -certamente porque mais lucrativos- à inversão de excedentes de capital produzidos internamente na economia goiana, e mesmo alhures.

Tais constatações obrigam-nos a buscar vias de explicação para o caso do desenvolvimento de uma economia tipicamente urbana em Goiânia diferentes das apresentadas pelos exemplos históricos clássicos, examinados exaustivamente pela literatura produzida em moldes acadêmicos em relação aos grandes centros industrial-capitalistas do Sudeste brasileiro e outros situados no litoral do país.

A fundação de Goiânia ocorreu na ocasião histórica em que, no Brasil, estando já sedimentadas as bases industriais de seus principais centros urbanos, toda a economia nacional foi compelida a adaptar-se a um novo modelo de desenvolvimento, o industrial-capitalista. Este modelo devia sustentar-se no mercado interno e, em consequência disto, exigia a instauração 
de uma nova divisão regional do trabalho no país. Nesta nova divisão, diferentemente do que se poderia esperar, a Goiás não estavam reservadas exclusivamente as funções de exportador de alimentos e matérias primas em bruto e importador de bens industrializados, produzidos pelo Sudeste. O novo modelo permitiu, pelo que se pode deduzir, com base no caso de Goiânia e de outras capitais brasileiras, o estabelecimento de um processo de relativa desconcentração territorial da indústria nacional.

Em relação a Goiás, por outro lado, desde aquela época que as oportunidades oferecidas ao capital mercantil para sobrepor-se ao produtivo devem ter-se reduzido acentuadamente. Em concomitância com o desenvolvimento de Goiânia e a consolidação de suas funções urbanas, nas novas condições do desenvolvimento brasileiro -servindo de núcleo de atração e irradiação de influxos inovadores, econômicos e sócio-culturais, advindos dessas novas condições nacionais-, ganhava impulso crescente, no território goiano, a disseminação da uma agropecuária em moldes empresariais modernos, caracterizada pelo uso de técnicas de produção intensivas em capital. E este fora apenas o primeiro passo para que, nos últimos tempos, viesse a se instalar ali um poderoso setor agroindustrial.

\section{Fontes impressas}

Associação comercial e industrial do estado de goiás - ACIEG. (1985). As maiores do ICM em Goiás. Goiânia: Pauta Editora.

Conselho de Imigração e Colonização - CIC. (Org.). (1949). Goiás. Um nova fronteira humana. Rio de Janeiro: CIC.

Diário Oficial do Estado de Goiás. Goiânia, Ano 123, No. 6.211, 1-47.

Elis, B. Goiânia: nasce uma cidade. Em Prefeitura de Goiânia (Org.). (1985). Memória cultural (pp. 45-59). Goiânia: Gráfica Ipiranga.

Governo Mauro Borges Teixeira. (1961). Plano de desenvolvimento econômico de Goiás. Goiânia: s/e, Vol. I e II.

Monteiro, O. (1938). Como nasceu Goiânia. São Paulo: Empresa Gráfica da Revista dos Tribunais.

Teixeira, P. L. (1939). Relatório apresentdo ao Exmo. Snr. Presidente da Repúblicapelo Dr. Pedro Ludovico Teixeira, Interventor Federal - 1939. Goiânia: Imprensa Oficial.

\section{Referências}

Arrais, T. A. (2004). Geografia contemporânea de Goiás. Goiânia: Editora Vieira.

Bertran, P. (1988). Uma introdução à História Econômica do Centro-Oeste do Brasil. Goiânia: Codeplan - Goiás, Universidade Católica de Goiás.

Bertran, P. (1983). Estruturação e processo de crescimento na economia de Goiânia. Cadernos INDUR, 3 (3), 87-91. 
Bertran, P. (1984). Goiânia: estrutura econômica e mudanças. Cadernos INDUR, 4 (4), 96-105.

Borges, B. (1990). O despertar dos dormentes. Goiânia: CEGRAF, UFG.

Campos, F. I. (1985). Questão Agrária: bases sociais da política goiana, 1930-1964. Tese doutorado em Ciências Sociais, Universidade de São Paulo.

Cardoso, M. F. (1988). Organização urbana. Em A. Duarte. Região Centro-Oeste (189-239). Rio de Janeiro: IBGE/Diretoria de Geociências.

Ferrari, O. F. (1988). Indústria. Em A. Duarte. Região Centro-Oeste (171-188). Rio de Janeiro: IBGE/Diretoria de Geociências.

Gonçalves, N. N. (1984). Evolução do parcelamento urbano de Goiânia - perspectiva histórica. Cadernos do INDUR, Goiânia, 4 (4), 9-39.

Instituto Brasileiro de Geografia E Estatística - IBGE (1957). Enciclopédia dos municípios brasileiros.. Vol II. Rio de Janeiro: IBGE.

Katzman, M. (1977). Cities and frontiers in Brazil. Cambridge: Harvard University Press.

Miranda, T. (1980). Caracterização da invasão do bairro Esplanada do Anicuns, no contexto urbano de Goiânia. Cadernos do INDUR, 2 (2), pp. 68-86.

Oliveira, F. de. (1989). A economia da dependência imperfeita. Rio de Janeiro: Grahal.

Rabelo, F. C. (1979). Governo Mauro Borges. Tradicionalismo, planejamento e mobilização social em Goiás. Belo Horizonte. Dissertação, mestrado em Ciência Política. Universidade Federal de Minas Gerais.

Silva, L. S. D. da. (2002). Progresso e sertão goiano: a espera. Em T. Botelho (Org.). Goiânia: cidade pensada. Goiânia: UFG Editora.

Solis, S. (1989). A economia de transição na cidade do Rio de Janeiro. Rio de Janeiro: Centro de Memória Social Brasileira/Conjunto Cândido Mendes. (Mimeo) 